\title{
An investigation of the mechanical properties of organic silica, bamboo leaf ash and rice husk reinforced aluminium hybrid composite
}

\begin{abstract}
Aluminium Metal Matrix Composites has continually generated a lot of interest due to the versatility of its application, lower cost of production and its outstanding properties. This study was carried out on the mechanical behavior of an aluminium 6063 based composite reinforced with bamboo based leaf (BLA) and rice husk ash (RHA). The chemical composition of each of the Al-Mg-Si alloy, BLA and RHA was determined; different kinds of characterization and microstructural analysis were also carried out to investigate the mechanical properties. The ultimate tensile strength values of the developed composites revealed that $10 \mathrm{wt} \%$ reinforced composites are superior to that of unreinforced alloy. Similarly, the yield strength values of the reinforced composites are superior to that of unreinforced alloy. $78.4 \%$ and $80.0 \%$ improvement were observed in comparison with unreinforced alloy. The \% elongation values were invariant to the weight ratio of BLA and RHA. Among all the composites investigated, $10 \mathrm{wt} \%$ composites reinforced with $75 \%$ BLA and 25\% RHA together with $10 \mathrm{wt} \%$ composites reinforced with equal percentage of BLA and RHA exhibited the highest hardness value of 46.4 and 42.2 respectively. Also, from the optical microstructures of the Al-BLA/RHA- $8 \mathrm{wt} \%$ and $10 \%$ hybrid composite, it is observed that the reinforcing particles (BLA and RHA) are visible and clearly delineated in the microstructure. The particles are fairly well distributed in the Al matrix and signs of particle clusters are minimal.
\end{abstract}

Keywords: aluminium, hybrid mmcs, organic silica, bamboo leaf ash, composites, rice husk ash, $\mathrm{Al} 6063$
Volume 3 Issue 4 - 2019

\author{
Oladayo Olaniran, ${ }^{1,2}$ Osemvinvie Uwaifo,' \\ Emmanuel Bamidele, ${ }^{3}$ Bolanle Olaniran ${ }^{4}$ \\ 'Department of Metallurgical and Materials Engineering, Federal \\ University of Technology, Nigeria \\ ${ }^{2}$ Department of Chemical Engineering, Texas Tech University, \\ USA \\ ${ }^{3}$ Department of Metallurgy, University of Johannesburg, South \\ Africa \\ ${ }^{4}$ Department of Communication Studies, Texas Tech University,
} USA

Correspondence: Oladayo Olaniran, Department of Metallurgical and Materials Engineering, Federal University of Technology, PMB 704,Akure, Nigeria,

Email oladayolaniran@gmail.com

Received: November 23, 2018 | Published: July 23, 2019
Abbreviations: BLA, bamboo based leaf; RHA, rice husk ash; MMCs, metal matrix composites; AHCs, aluminium hybrid composites

\section{Introduction}

The availability of diverse materials has posed a big challenge of materials selection for different engineering applications. ${ }^{1}$ However; this has enhanced the preference for affordable high performance materials with requisite quality. Metal Matrix Composites (MMCs) has emerged as a viable alternative to different conventional materials. ${ }^{2}$ The application of these composites have been established in different industries such aerospace, marine, defense and automobile. Metals such as copper, aluminium, magnesium and their alloys are the most commonly used MMCs due to their light weights. The unique properties of these metals are combined with different kind of reinforcement materials to produce composite materials of distinct properties..$^{3-6}$ Aluminium based composites has continually generated a lot of interest judging from the available volume of literature. The versatility of its application, lower cost of production and its outstanding properties have distinguished $\mathrm{Al}$ based composites and it has remained the most used MMC. ${ }^{2}$ The reinforcement materials selected with $\mathrm{Al} \mathrm{MMC}$ is very crucial in harnessing the desired property. In different research, numerous reinforcement materials such as fly ash, silicon carbide, alumina, silica, graphite, mica among others have been selected with Aluminium MMCs.
However, the areas of application of Al based composites is expected to continue growing. Therefore, different combinations of important reinforcement materials particularly agro waste products including bamboo leaf ash and rice husk require further study.

Different literatures have studied the potentials of agro waste products as adequate reinforcement materials, findings have shown that $\mathrm{Al}$ based composites reinforced with synthetic ceramics including alumina and silicon carbide have superior properties in comparison to the agro waste ash reinforced grades. In this paper, our aim is to consider the potentials of bamboo leaf ash (BLA) and Rice Husk Ash (RHA) as complimenting reinforcement for the development of low cost-high performance Aluminium Hybrid Composites (AHCs).

\section{Materials and methods}

\section{Materials}

Al-Mg-Si alloy billets - with chemical composition determined using spark spectrometric analysis as shown in Table 1 was selected as $\mathrm{Al}$ matrix for this investigation. For the hybrid reinforcing phases, bamboo leaf ash (BLA) and rice husk ash (RHA) $(<50 \mu \mathrm{m})$ derived from controlled burning and sieving of dry bamboo leaves and rice husk were used as reinforcement for the Al matrix. Magnesium was procured for use in improving wettability between the Al matrix and the reinforcements.

Table I Chemical composition of Al-Mg-Si alloy billet in weight percentages

\begin{tabular}{llllllllllllll}
\hline Elements & $\mathrm{Si}$ & $\mathrm{Fe}$ & $\mathrm{Cu}$ & $\mathbf{M n}$ & $\mathbf{M g}$ & $\mathrm{Zn}$ & $\mathrm{Ti}$ & $\mathbf{N i}$ & $\mathrm{Sn}$ & $\mathrm{Pb}$ & $\mathrm{Ca}$ & $\mathbf{V}$ & $\mathbf{A l}$ \\
\hline$w t \%$ & 0.4 & 0.22 & 0.008 & 0.011 & 0.396 & 0.02 & 0.013 & 0.01 & 0.002 & 0.001 & 0.002 & 0.003 & 98.88 \\
\hline
\end{tabular}




\section{Methods}

Preparation of bamboo leaf ash (BLA): Dry bamboo leaves were gathered from FUTA environment near the forest circle having a large mass of bamboo trees. The collected bamboo leaves were placed in a metallic drum and fired in open air to allow for thorough combustion. The ash produced from the burning process was allowed to cool for 24 hours before removal from the drum. The ash was then conditioned using a muffle furnace at a temperature of $650^{\circ} \mathrm{C}$ for 3 hours. Sieving of the bamboo leaf ash was then performed using a sieve shaker to obtain ashes with mesh size under $50 \mu \mathrm{m}$.

Preparation of rice husk ash (RHA): A simple metallic drum with perforations to allow for air circulation to aid combustion was used as burner for the preparation of the RHA. Dry rice husks were placed inside the drum while charcoal, which served as the fire source was used to ignite the rice husk. The husk was left to burn completely and the ashes removed $24 \mathrm{hr}$ later. The ash was then conditioned by heat-treating the ash at a temperature of $650^{\circ} \mathrm{C}$ in an electric furnace for $180 \mathrm{mins}$ to reduce the carbonaceous and volatile constituents of the ash.

Composite production: Two step stir casting process was utilized to produce the composites. The process started with the determination of the quantities of RHA and BLA required to produce 6 and $10 \mathrm{wt} \%$ reinforcement consisting of $0: 1,1: 2,1: 4,1: 6$, and 1:8 RHA and BLA weight percents, respectively and marked as $\mathrm{B}, \mathrm{C}, \mathrm{D}, \mathrm{E}$ and $\mathrm{F}$ while the unreinforced was marked as A. The RHA and alumina were initially preheated at a temperature of $250^{\circ} \mathrm{C}$ to remove moisture and to help improve wettability with the $\mathrm{Al}-\mathrm{Mg}-555 \mathrm{n}$ Si alloy melt. The $\mathrm{Al}-\mathrm{Mg}-$ Si alloy ingots were charged into a gas-fired crucible furnace and heated to a temperature of $750 \pm 30^{\circ} \mathrm{C}$ (above the liquids temperature of the alloy) to ensure the alloy melts completely. The liquid alloy was then allowed to cool in the furnace to a semi solid state at a temperature of about $600^{\circ} \mathrm{C}$. The preheated RHA and BLA particulates were added at this temperature $\left(600^{\circ} \mathrm{C}\right)$ and stirring of the slurry was performed manually for $5-10 \mathrm{~min}$. The composite slurry was then superheated to $800 \pm 30^{\circ} \mathrm{C}$ and a second stirring performed using a mechanical stirrer. The stirring operation was performed at a speed of $400 \mathrm{rpm}$ for $10 \mathrm{~min}$ to help improve the distribution of the particulates in the molten $\mathrm{Al}$ $\mathrm{Mg}-\mathrm{Si}$ alloy. The molten composite was then cast into prepared sand moulds inserted with chills. Lathe machine was used to produce the composite into a smooth rod-like shape and to reduce the samples into the dimensions suitable for mechanical testing. Microstructural examination was carried out using Zeiss Metallurgical Microscope with accessories for image analysis. Hardness, tensile and wear testing were also carried out on the specimens. The fracture toughness evaluation was done also.

\section{Results}

\section{Chemical composition of materials}

The chemical composition of $\mathrm{Al}-\mathrm{Mg}-\mathrm{Si}$ alloy billet in weight percentages is shown in Table 1, while Tables $2 \&$ Table 3 presents the chemical composition of BLA and RHA.

Table 2 Chemical composition of bamboo leaf ash in weight percentages

\begin{tabular}{|c|c|c|c|c|c|c|c|c|c|c|}
\hline Composition & $\mathrm{SiO}_{2}$ & $\mathrm{Al}_{2} \mathrm{O}_{3}$ & $\mathrm{ZnO}$ & $\mathrm{CaO}$ & $\mathrm{MgO}$ & $\mathrm{Na}_{2} \mathrm{O}$ & $\mathbf{K}_{2} \mathbf{O}$ & $\mathrm{Fe}_{2} \mathrm{O}_{3}$ & $\mathrm{TiO}_{2}$ & Others \\
\hline$w t \%$ & 76 & 4.2 & I.18 & 7.25 & 1.9 & 0.22 & 5.8 & 1.4 & 0.20 & 1.85 \\
\hline
\end{tabular}

Table 3 Chemical composition of rice husk ash in weight percentages

\begin{tabular}{lllllllll}
\hline Constituents & $\mathrm{SiO}_{2}$ & $\mathbf{C}$ & $\mathrm{CaO}$ & $\mathbf{M g O}$ & $\mathbf{K}_{2} \mathbf{O}$ & $\mathrm{Fe}_{2} \mathbf{O}_{3}$ & $\mathbf{O t h e r s}$ \\
\hline$w t \%$ & 91.56 & 4.8 & 1.5 & 0.53 & 0.39 & 0.21 & 0.93 & \\
\hline
\end{tabular}

\section{Tensile test}

The result of tensile test to determine the ultimate tensile strength, yield strength, strain energy stored, strain to fracture, and fracture toughness of the produced composites are presented in Figure (1-5) respectively.

\section{Hardness and wear tests}

The result of the hardness testing is shown in Figure 6. The variation of the wear resistance obtained is presented in Figure 7 while Figure 8 displays the variation of wear rate of hybrid reinforced Al/BLA-RHA composite.

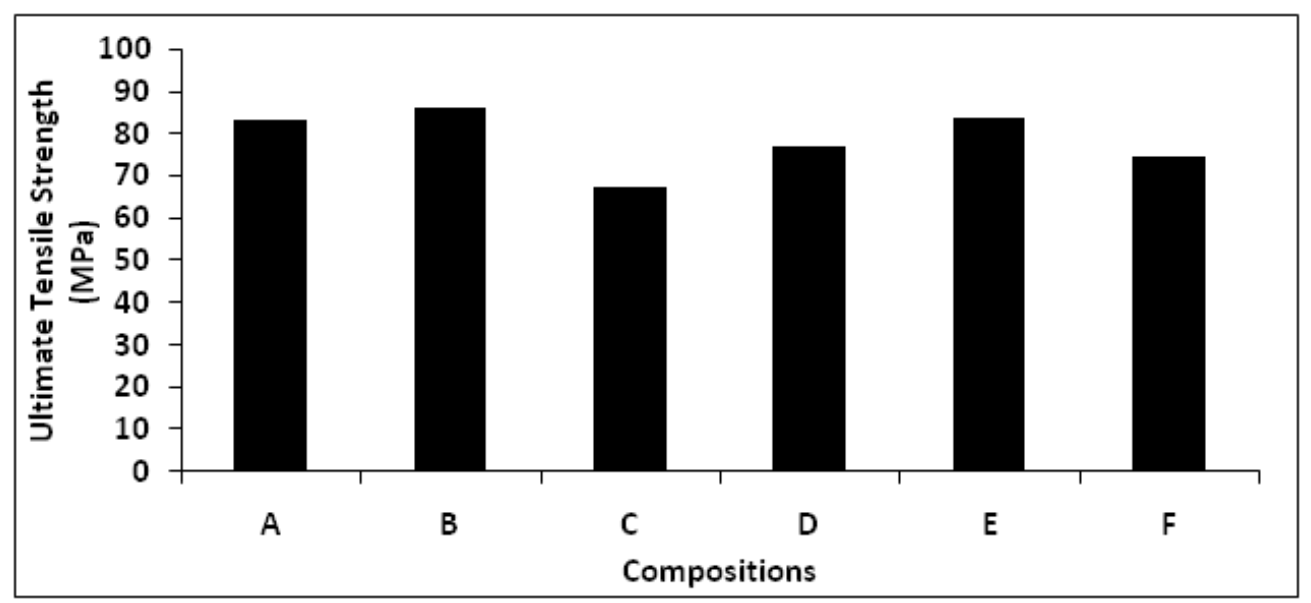

Figure I Variation of ultimate tensile strength of hybrid reinforced Al/BLA-RHA composite. 


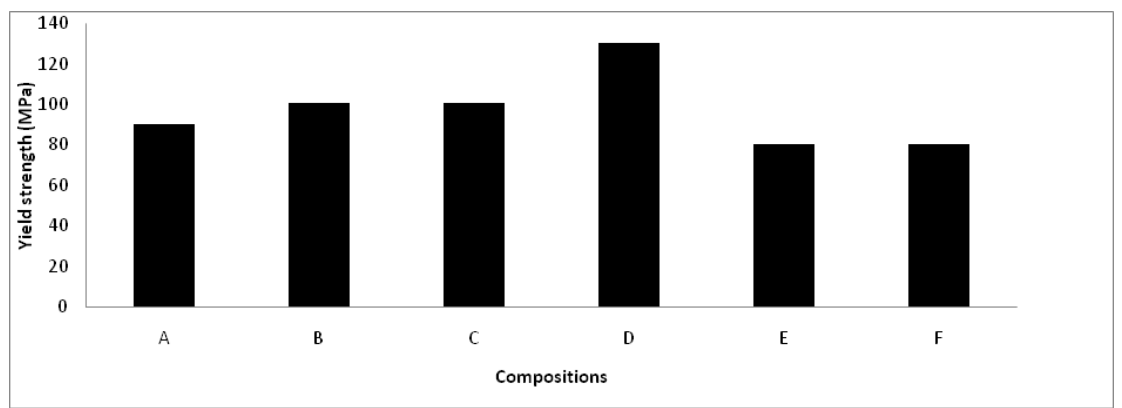

Figure $\mathbf{2}$ Variation of Yield strength of hybrid reinforced Al/BLA-RHA composite.

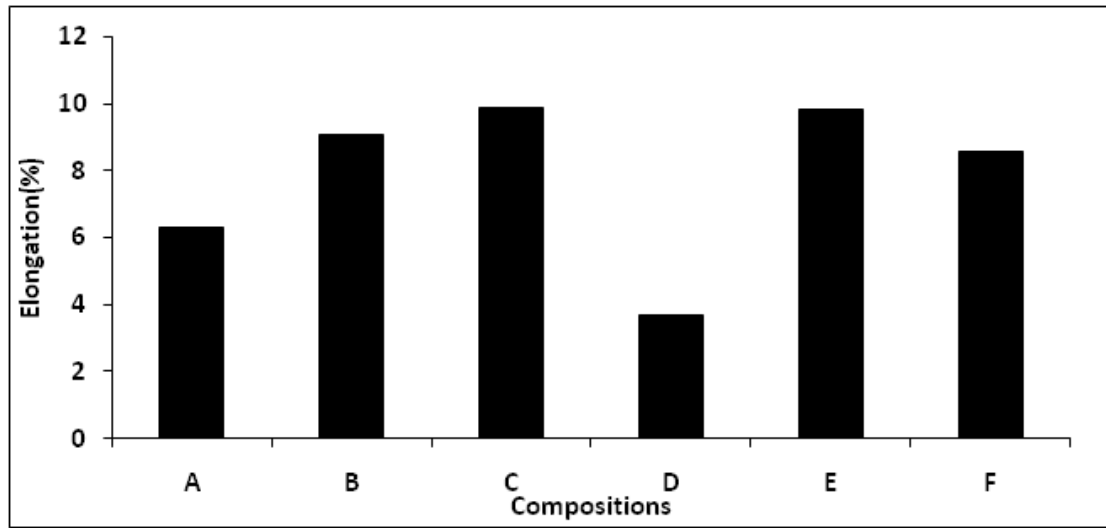

Figure 3 Variation of percentage elongation of hybrid reinforced Al/BLA-RHA composite.

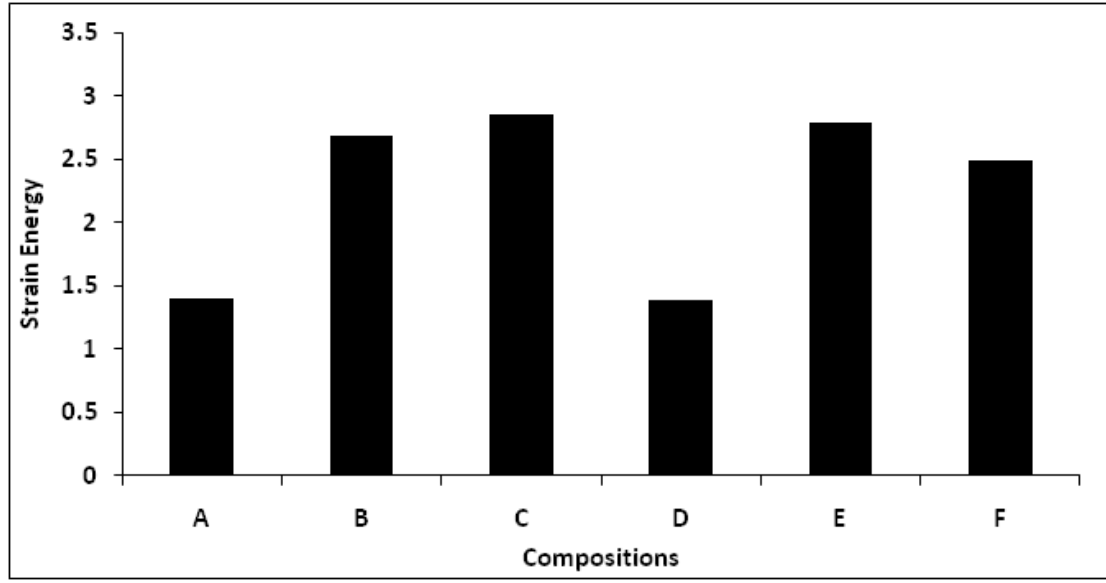

Figure 4 Variation of strain energy of hybrid reinforced Al/BLA-RHA composite.

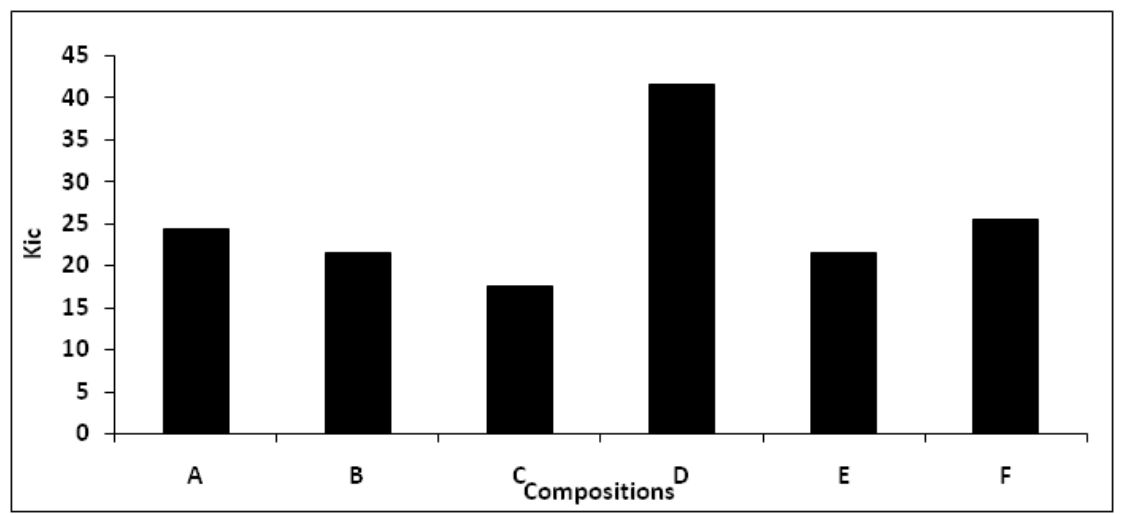

Figure $\mathbf{5}$ Variation of fracture toughness of hybrid reinforced Al/BLA-RHA composite.

Citation: Olaniran O, Uwaifo O, Bamidele E, et al.An investigation of the mechanical properties of organic silica, bamboo leaf ash and rice husk reinforced aluminium hybrid composite. Material Sci \& Eng. 2019;3(4):I29-134. DOI: 10.15406/mseij.2019.03.00103 




Figure 6 Variation of hardness of hybrid reinforced Al/BLA-RHA composite.

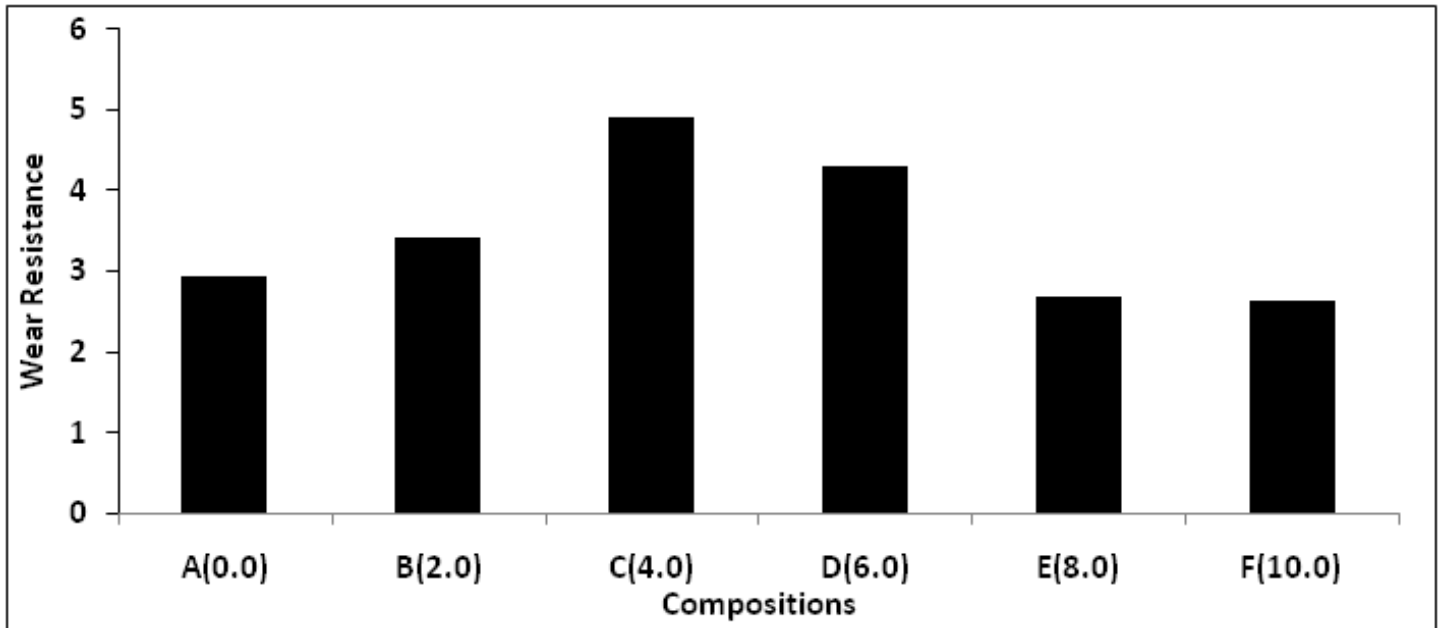

Figure 7 Variation of wear resistance of hybrid reinforced Al/BLA-RHA composite.

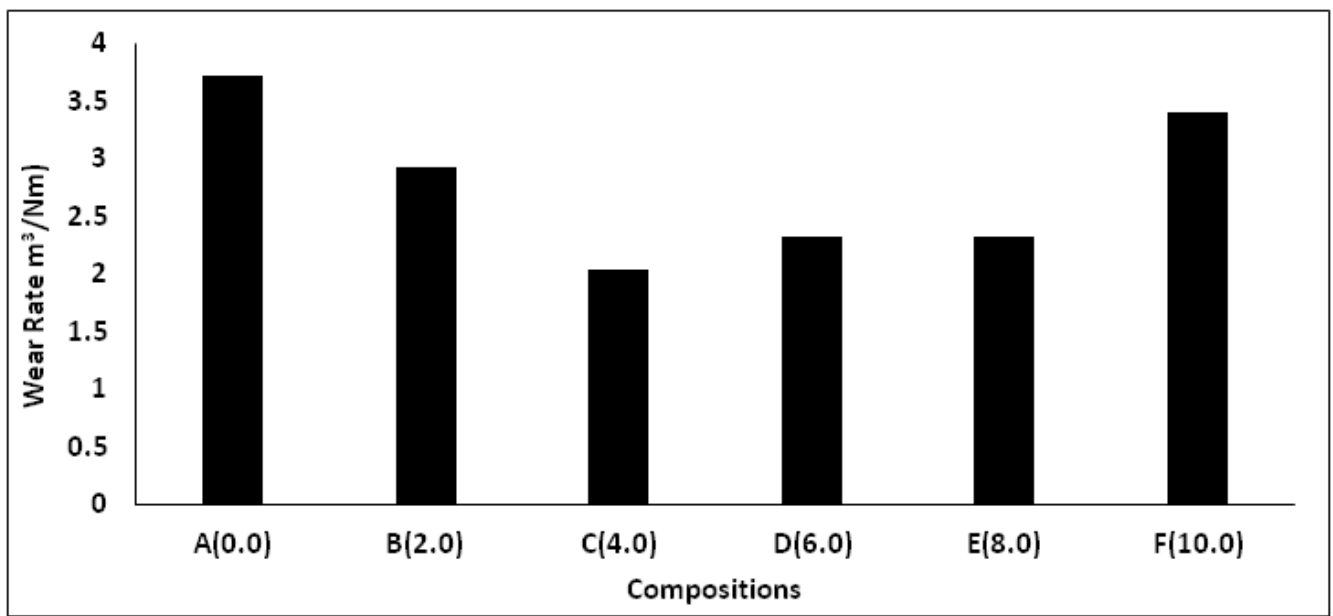

Figure $\mathbf{8}$ Variation of wear rate of hybrid reinforced Al/BLA-RHA composite. 


\section{Microstructural examination}

Figure 9.

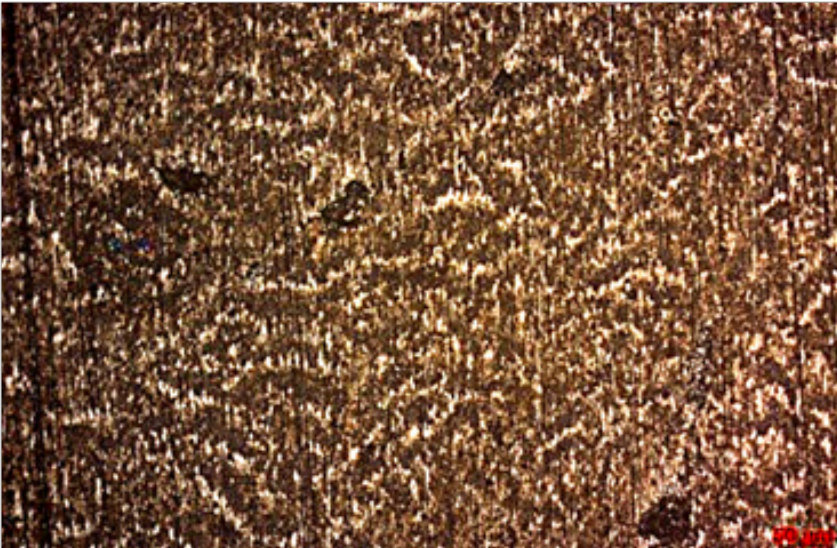

(A)

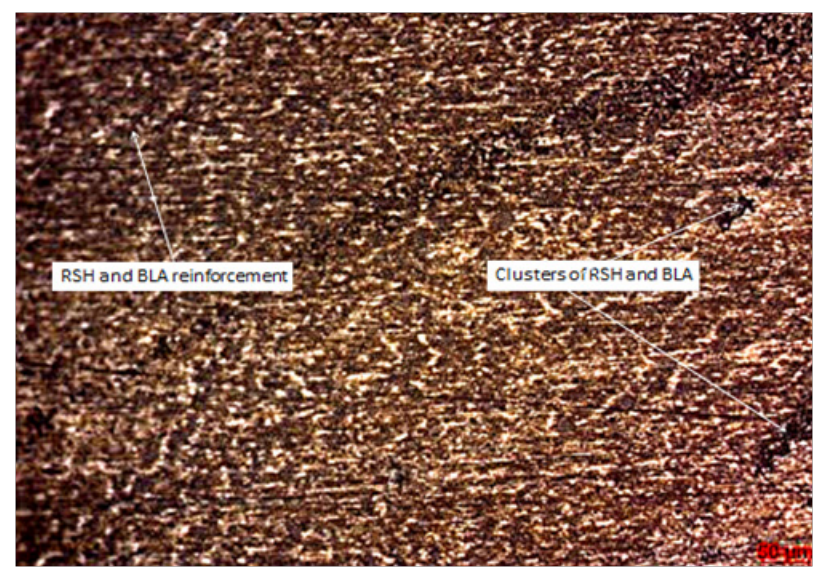

(C)

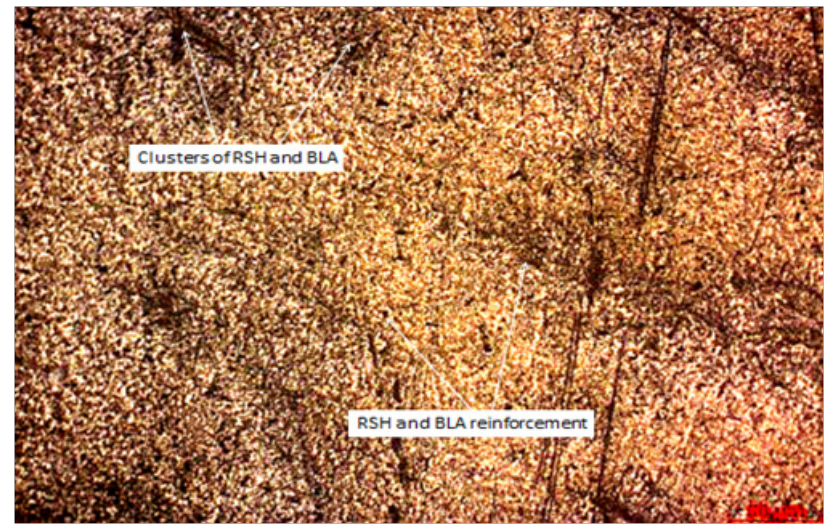

(E)

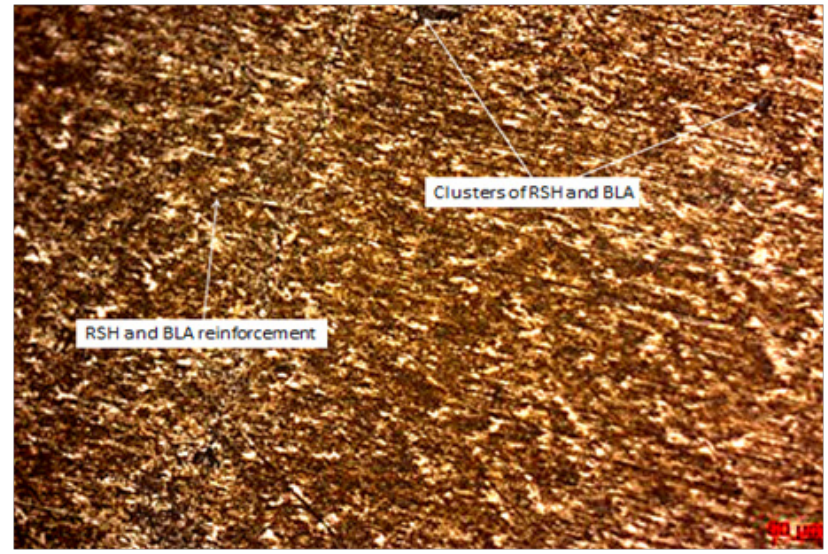

(B)

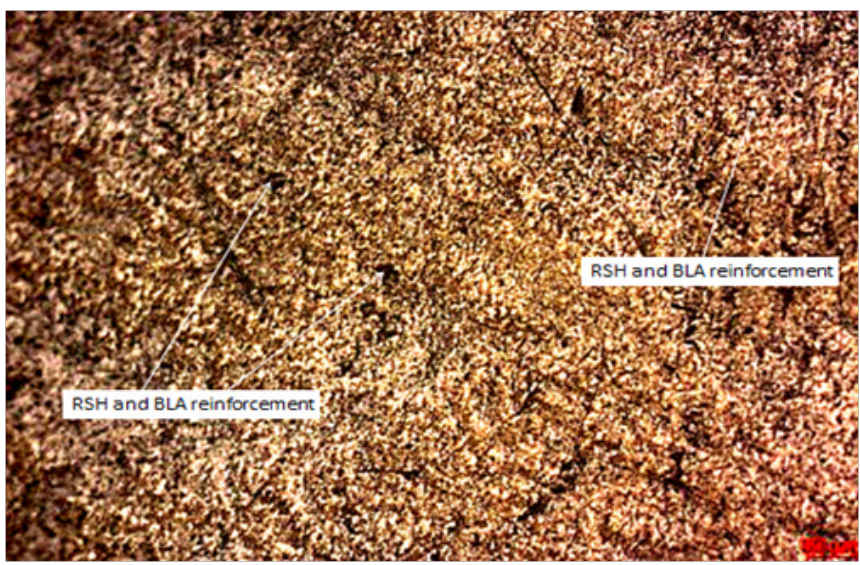

(D)

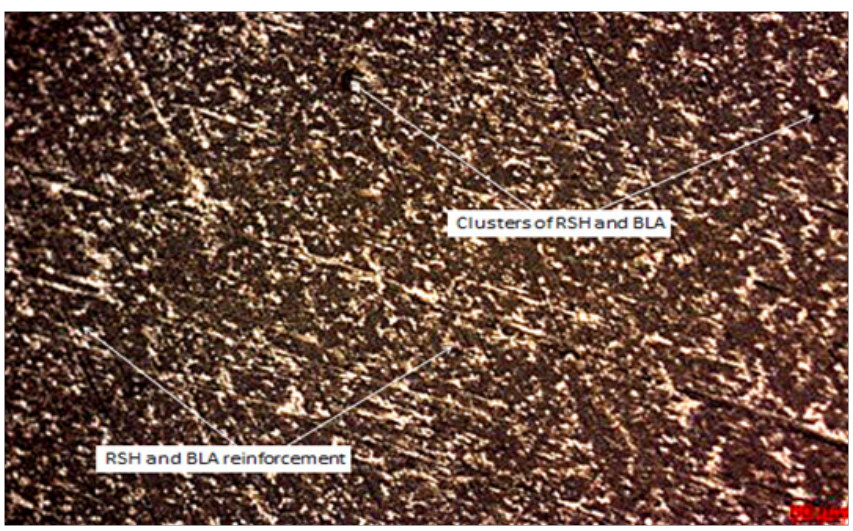

( $\mathrm{F})$

Figure 9 Representative micrographs of composites with 8wt\% and I0\%wt reinforcement containing BLA:RHA (A)0:I (B) I:2 (C) I:4 (D) I:6 (E) I:8 (F) I:I0.

\section{Discussion}

The ultimate tensile strength of the developed composites hybrid reinforced Al/BLA-RHA - as observed in Figure 1 shows that $10 \mathrm{wt} \%$ reinforced composites are superior to that of unreinforced alloy. A maximum UTS value of 135.76 and $136 \mathrm{MPa}$ were obtained for $10 \mathrm{wt} \%$ composite sample reinforced with $50 \%$ BLA and $6 \mathrm{wt} \%$ composite reinforced with $50 \%$ RHA. This implies an increment of $78.4 \%$ and $80.0 \%$ respectively in comparison with unreinforced alloy. Similar trend is also observed for the yield strength values depicted by Figure 2, the yield strength values of the reinforced composites are superior to that of unreinforced alloy, with $10 \mathrm{wt} \%$ composite sample 
reinforced with $100 \%$ BLA and $6 \mathrm{wt} \%$ composite reinforced with $75 \%$ RHA exhibiting the maximum yield strength values of $101.25 \mathrm{MPa}$ and $102.2 \mathrm{MPa}$ respectively. This also shows an improvement of $78.4 \%$ and $80.0 \%$ respectively in comparison with unreinforced alloy. The $\%$ elongation values in Figure 4 were invariant to the weight ratio of BLA and RHA. A scatter was observed with the \% elongation of the composite within the range $10.47 \%-16.3 \%$. These are within the range reported by literature. ${ }^{8}$

The fracture toughness values in comparison with unreinforced alloy with the exception of samples containing 50\% BLA and 50\% RHA in $10 \mathrm{wt} \%$ composite as well as $6 \mathrm{wt} \%$ composite reinforced with $100 \%$ BLA also agrees with the previous work reported by. ${ }^{8}$ The variation of micro - hardness values of hybrid composites sample are presented in Figure 6. Among all the composites investigated, $10 \mathrm{wt} \%$ composites reinforced with $75 \%$ BLA and $25 \%$ RHA together with $10 \mathrm{wt} \%$ composites reinforced with equal percentage of BLA and RHA exhibited the highest hardness value of 46.4 and 42.2 respectively. This also implies an increment of $21.7 \%$ and $13.4 \%$ respectively in comparison with unreinforced alloy. These trends can be attributed to the presence of BLA and RHA in the reinforced composites. ${ }^{9}$ Have reported that the basic mechanism of composite deformation is a load transfer from matrix to reinforcement and good bonding between matrix and reinforcement gives rise to better load transfer and improved properties. ${ }^{10}$ Also affirmed that in particulate reinforced composites, the load on the matrix gets transferred to the reinforcing elements thereby increasing the load bearing capacity of the composites. With increase in volume fraction of filler material, more loads get transferred to reinforcement which leads to increase in tensile strength. Figure 9 shows the optical microstructures of the Al-BLA/RHA- $8 \mathrm{wt} \%$ and $10 \%$ hybrid composite. It was observed that the reinforcing particles (BLA and RHA) are visible and clearly delineated in the microstructure. The particles are fairly well distributed in the $\mathrm{Al}$ matrix and signs of particle clusters are minimal. For the microstructural images, partial dispersion of reinforcing particles (BLA and RHA) within the matrix (Al) was observed.

\section{Conclusion}

The mechanical properties of $\mathrm{Al}$ (6063) hybrid composites reinforced with Bamboo leaf ash and rice husk ash have been investigated. From the different observations and results obtained from this investigation, it can be concluded that:

I. The hardness, tensile strength and yield strength of the composites samples were superior to that of unreinforced alloy.

II. Maximum increase in ultimate tensile strength and yield strength of $78.4 \%$ and $80.0 \%$ were observed for $10 \mathrm{wt} \%$ composites sample reinforced with $100 \%$ BLA and $6 \mathrm{wt} \%$ composite sample reinforced with $75 \%$ RHA respectively

III. The \% elongation values of composites sample were invariant to the weight ratio of BLA and RHA.
IV. The fracture toughness values of hybrid composites samples were also found to be superior to that of the unreinforced alloy with the exception of samples containing 75\% BLA and $100 \%$ BLA in $10 \mathrm{wt} \%$ composites as well as $6 \mathrm{wt} \%$ composites reinforced with $100 \%$ BLA

V. From the result obtained BLA and RHA has great potential to serve as complementing reinforcement for the development of low cost-high performance Aluminium hybrid composite.

\section{Funding details}

None.

\section{Acknowledgments}

None.

\section{Conflicts of interest}

Authors declare that there are no conflicts of interest.

\section{References}

1. Mazumdar S. Composites manufacturing: materials, product, and process engineering. CRC press; 2001.

2. Kumar BP, Birru AK. Microstructure and mechanical properties of aluminium metal matrix composites with addition of bamboo leaf ash by stir casting method. Trans Nonferrous Met Soc China. 2017;27(12):25552572 .

3. Ravesh SK, Garg TK. Preparation \& analysis for some mechanical property of aluminium based metal matrix composite reinforced with SiC \& fly ash. Int J Eng Res Appl. 2012;2(6):727-731.

4. Khosravi H, Bakhshi H, Salahinejad E. Effects of compocasting process parameters on microstructural characteristics and tensile properties of A356-SiCp composites. Trans Nonferrous Met Soc China. 2014;24(8):2482-2488.

5. Yuan $\mathrm{HU}$, Chen Y, Li L, et al. Microstructure and properties of $\mathrm{Al} / \mathrm{Cu}$ bimetal in liquid-solid compound casting process. Trans Nonferrous Met Soc China. 2016;26(6):1555-1563.

6. Radhika N, Raghu R. Development of functionally graded aluminium composites using centrifugal casting and influence of reinforcements on mechanical and wear properties. Trans Nonferrous Met Soc China. 2016;26(4):905-916

7. Rohatgi P, Schultz B. Lightweight metal matrix nanocompositesstretching the boundaries of metals. Mater Matters. 2007;2(4):16-20.

8. Alaneme KK. Mechanical Behaviour of Cold Deformed and Solution Heat-treated Alumina Reinforced AA 6063 Metal Matrix Composites. West Indian J Eng. 2013;35(2):31-35

9. Pukanszky B, Vörös G. Mechanism of interfacial interactions in particulate filled composites. Compos Interfaces. 1993;1(5): 411-427.

10. Chawla N, Shen Y. Mechanical behavior of particle reinforced metal matrix composites. Adv Eng Mater. 2001;3(6):357-370. 